\title{
The Effects of Functional Training on Pain, Function, and Performance in Taekwondo Players with Mechanical Low Back Pain
}

\section{Pouya Rabiei ${ }^{1}$, Behnaz Ganji Namin ${ }^{1}$, Mohammad Hosein Nasermelli' ${ }^{1}$, Omid Marjomaki², Vahid Mazloum 1}

\footnotetext{
${ }^{1}$ Department of Physical Education and Sports Sciences, Karaj Branch, Islamic Azad University, Karaj, Iran ${ }^{2}$ Independent Researcher, Karaj, Iran

Email: Pouya_rabiei@yahoo.com, behnezganji@yahoo.ocm,mh.naser.m@gmail.com, marjomaki@gmail.com, vahid.mazloum@yahoo.com
}

\begin{abstract}
How to cite this paper: Rabiei, P., Namin, B.G., Nasermelli, M.H., Marjomaki, O. and Mazloum, V. (2017) The Effects of Functional Training on Pain, Function, and Performance in Taekwondo Players with Mechanical Low Back Pain. Health, 9, 1176-1189.

https://doi.org/10.4236/health.2017.98085
\end{abstract}

Received: June 16, 2017

Accepted: August 20, 2017

Published: August 23, 2017

Copyright $\odot 2017$ by authors and Scientific Research Publishing Inc. This work is licensed under the Creative Commons Attribution International License (CC BY 4.0).

http://creativecommons.org/licenses/by/4.0/

\begin{abstract}
Background: The aim of this study was to assess the effects of functional training (FT) on pain, function, and performance in elite male taekwondo players with CMLBP. Method: 27 elite male taekwondo players (mean \pm standard deviation: age $24.4 \pm 4.9$ years, body mass $75.7 \pm 15.1 \mathrm{~kg}$, height $181.4 \pm 7.8 \mathrm{~cm})$ were allocated to two experimental $(\mathrm{n}=15)$ and control $(\mathrm{n}=$ 12) groups. The eight-week FT was divided into four distinct phases for the subjects of the experimental group. Variables of pain and function were assessed by Visual Analogue Scale (VAS) and Oswestry Disability Index (ODI), respectively. The movement time of Ap Douliou Chagi kick (MTAK) and speed of Ap Douliou Chagi kick (SAK) was used for the variable of performance. Results: Considering the results of pre-test before the implementation of the scores protocol, after FT intervention, VAS $(\mathrm{p}=0.004)$, ODI $(\mathrm{p}=0.005)$, MTAK on the right leg $(\mathrm{p}=0.029)$ and the left leg $(\mathrm{p}=0.013)$ decreased and SAK on both legs $(\mathrm{p}=0.000)$ increased significantly in comparison with the control group. Conclusion: It is assumed that FT can reduce the pain intensity and improve the function and performance in taekwondo players.
\end{abstract}

\section{Keywords}

Low Back Pain, Functional Training, Muscular Subsystems, Performance, Taekwondo

\section{Introduction}

Low back pain is one of the most common musculoskeletal disorders that most 
people of the world have experienced at least once in their lives. Low back pain is usually considered as a self-limiting pain. But approximately $16 \%$ to $62 \%$ of acute cases may develop chronic (more than 3 months) pain and its recurrence rate has been estimated as high as $85 \%$ [1] [2] [3]. Low back pain can be considered as the first cause of disability and absenteeism in industrialized societies, exerting a large burden on the health care system [1]. Some researchers have pointed out in their studies that people who report low back pain often have reduced spinal motion, particularly spinal extension [2] [4]. Reduced spinal extension can be classified as being either general (i.e., total spine) or segmental (i.e., on vertebral level) that will also affect people's efficiency in the society [4].

Low back pain can be sub-divided into Specific and Nonspecific. Specific low back pain can occur because of disc-related pain, idiopathic pain, infection, tumor, osteoporosis or fracture [5]. Meanwhile, mechanical or nonspecific low back pain is the most common type of low back pain that has been reported by many [1] [2] [6]. In chronic mechanical low back pain (CMLBP), imbalance typically occurs between the functional load, which is the effort required for work and daily activities, and the ability, which is potential for performing these activities [6]. This kind of low back pain is characterized by no structural change; that is, there is no disc space reduction, nerve root compression or impingement, joint or bone injuries, marked spinal malformation that may lead to back pain [6].

Studies have shown that other than non-athletes, players at even the highest functional levels also experience low back pain, where the cause of low back pain will be different according to the type of sports activity [7]. For example, CMLBP has been reported as one of the common pains in taekwondo 8. The research has shown that the low back has been recognized as the third most injured body region in adult Canadian elite taekwondo players [8]. Although there are data in which frequently occurring of CMLBP in Judo and Karate players was noted, there is lack of studies that focus on frequently occurring of CMLBP syndrome on Taekwondo players [9] [10].

Several methods have been recommended for the management of CMLBP and exercise is included one of these methods however the most effective form of exercise as a method of rehabilitation for CMLBP is unknown [11] reflecting its complexity [12] and more research is required [13]. Stabilizing the trunk and normalizing the length and strength of the trunk muscles, which play a significant role in low back pain occurrence, to reduce the short- and long-term symptoms can be mentioned as some of the effects of exercise, which have been shown by clinical trials [1]. Furthermore, exercise can improve the support and stabilization of the lumbar spine, improving the proprioception related to the dysfunction and avoiding the pain [1].

In recent years, core stability exercises have been used broadly for the rehabilitation of low back pain, which has a positive effect on reducing pain, increasing the trunk stability, improving physical function, and also facilitating skilled motor 
behaviors in patients [1] [3]. As noted, instability in the lumbar region can be associated with low back pain. This instability may be combined with an imbalance in the muscle structure of the body. Therefore, stability in the lumbar region can be maintained by a focus on the role of muscles as a joint support system, muscles which are related to each other, create force couple (two equal and opposite muscle forces that produce pure rotation around a center of motion), and lead to stability in the posture by creating mutual function [4] [14]. These approaches are different from traditional approaches to muscles and exercise prescription. Groups of muscles that work together and influence each other in the production of a specific function, and which ultimately lead to stability in the posture, are called muscular chains [14]. There are three subtypes of muscular chains: synergists, muscle slings, and Myofascial chains [14]. To manage low back pain, it is important to emphasize the muscles as both locally separate functional units on one hand and the global stability function of muscles as muscular chains, which have been recognized as global muscular subsystems, on the other hand.

Based on it, there are few studies that consider both local and global roles of involved muscles in CMLBP in their interventions so the aim of present study was to investigate the effect of functional training (FT) which are designed based on the local and global stability subsystems and implemented in four phases on pain, function and performance of elite male taekwondo players with CMLBP and also provided scientific evidence for the validity of FT.

\section{Methods}

\subsection{Study Design}

The quasi-experimental research under the supervision of ethical committee of Islamic Azad University of Karaj, Karaj, Iranwith pre-test and post-test, which included a control group and random sampling, was used to assess the effects of FT, designed for four distinct phases-Inhibit, Lengthen, Activation, and Integration - on the pain, function and performance in elite male taekwondo players with CMLBP. The independent variable was FT and the dependent ones were pain, function and performance.

\subsection{Participants}

The statistical population of the present study consisted of male taekwondo players with CMLBP, aged between 20 and 35 years. Taekwondo players who participated in the research based on the inclusion criteria had the following conditions: having at least a black belt and above, at least 5 years of non-stop sports history, winning one of the top three medals in a national competition, membership in Premier League of Taekwondo, and history of membership in the national team and also exclusion criteria included: history of acute low back pain, surgery on the spine and lower limbs, injuries and diseases associated with the central nerve system, history of serious damage to the spine and hip, intervertebral 
disc damage, systemic and inflammatory disease, malignant Rheumatism, Cauda Equina syndrome, osteoarthritis, Rheumatoid Arthritis, malignant Spondylopathy syndrome, acute spinal canal stenosis, Spondylolysis and Spondylolisthesis or any specific factor which causes low back pain [3].

After recalling, 38 taekwondo players with low back pain referred for medical examination. Based on the diagnosis of a physician specialist in sports medicine and subjects' reports about chronic pain, which means the existence of pain for more than three months, as well as previous studies, therefore, 31 of subjects suffered from CMLBP syndrome and were selected as subjects of research. Then, considering the exclusion and inclusion criteria, the number of subjects was reduced to 27 people due to the exclusion of four subjects because of personal problems. Subjects were randomly assigned to two groups: experimental group and control group (Figure 1).

The allocation was concealed by a random numerical sequence in sealed envelopes in which the experimental and control groups were determined. Before initiating interventions, every participant chose one envelope and opened the chosen envelope. So, the group written on the envelope and in which subject had to attend was disclosed.

\subsection{Visual Analogue Scale}

To measure variable of pain in the pre-test and post-test, the Visual Analogue Scale (VAS) was used in the study. The subjects were asked to report the most severe pain experienced in specific taekwondo training condition. The average

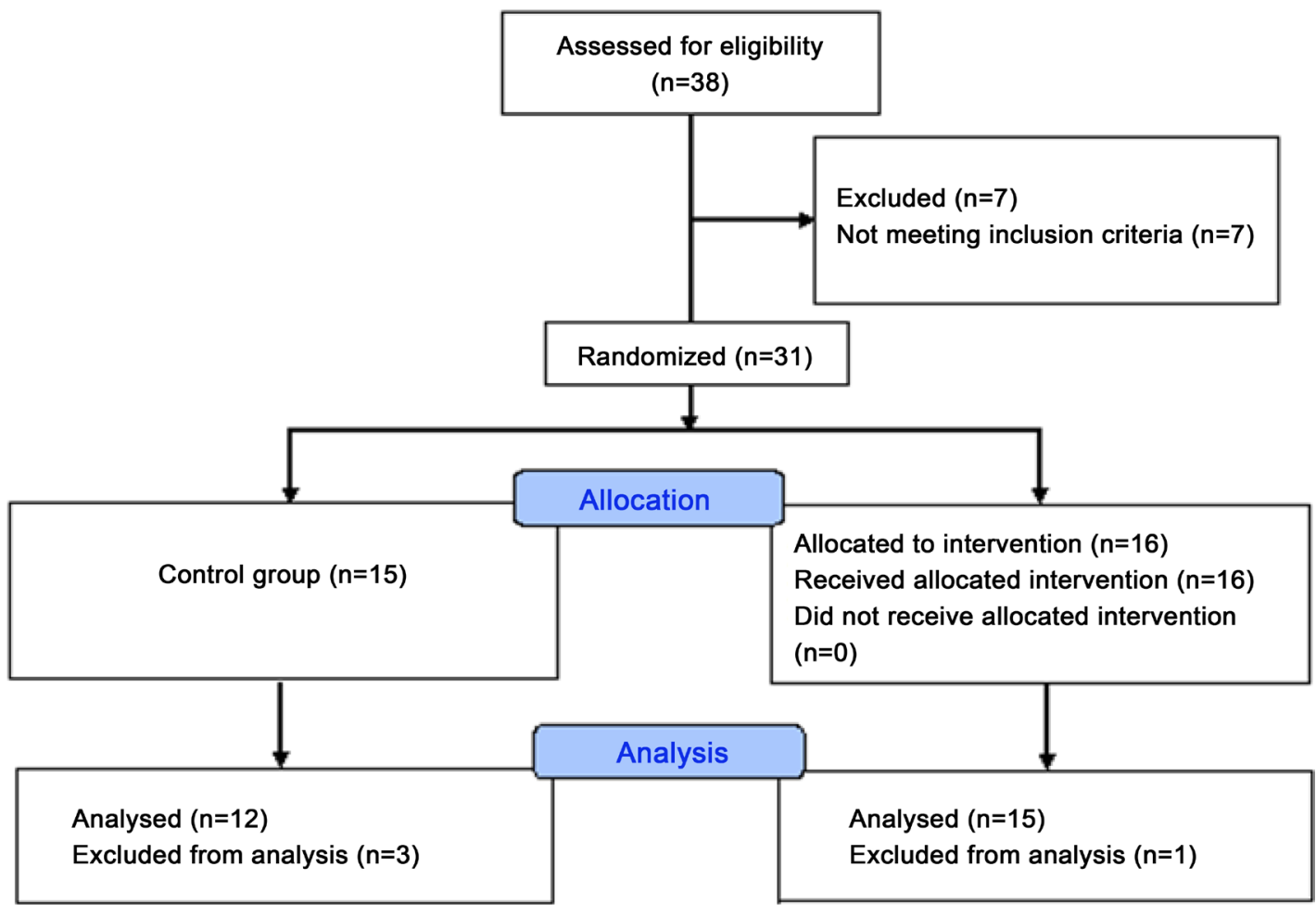

Figure 1. Flow diagram of the study. 
values of VAS have been calculated between 0 and 10 in all participants.

In this scale, score 0 means no pain and score 10 means the severest pain, which the participant cannot endure. This scale has been the most valid grading system for comparison between different periods and is widely used in research related to pain $(\mathrm{ICC}=0.91)[15]$.

\subsection{The Oswestry Disability Index}

The Oswestry Disability Index (ODI) was used to assess function. ODI is a questionnaire that is utilized to assess physical disability for low back pain (ICC $=$ 0.80). It includes six different parts: pain intensity, patient personal care, lifting, walking, sitting, standing, sleeping, social life, and traveling. For each section the total possible score is 5 : if the first statement is chosen the section score is 0 , and if the last statement is marked the section score is 5. Clearly, higher scores indicate more physical disability [16].

\subsection{The Test of Kick Speed and Test of Kick Movement Time}

Performance tests designed based on a research project of special talent Taekwondo (Pilate Iranian National Plan) [17]. To assess speed of Ap Douliou Chagi kick (SAK) the subject stood in front of two meets and performed the kick for 10 seconds, once with the left leg and then with the right leg. The number of kicks which were performed correctly within 10 seconds was counted. The implementation of the higher number of kicks indicated the higher ability of the athlete [17].

To assess movement time of Ap Douliou Chagi kick (MTAK) the subject was asked to stand in the former test position and hit a kick in the fastest possible time as soon as he hears the sound of whistle blow. The tester started the stopwatch when the sound of whistle blow was heard and stopped it when he heard the sound of the clash of the person's foot to the meet. This test was performed three times for each leg and the best time was considered as the movement time [17].

\subsection{The Training Intervention}

Exercise sessions included three sessions per week (each session with an average time of 60 minutes) and a total of 24 sessions, which were equivalent to eight weeks based on previous studies [18] [19] [20] [21]. In the first session, the training protocol involved all details provided for the subjects. The exercises of each week were explained, trained, and showed by an athletic trainer in the first session of the week for the subjects in the experimental group. It is noteworthy that in addition to training at the start of each week, during the implementation of the exercises, the athletic trainer learnt the correct manner of doing the exercises and their details by the use of Verbal, Tactile, and Visual reinforcement structural techniques [21]. Participants in the control group continued their taekwondo training and received no specific intervention. Considering the 
morality issues, the participants in control group received the exercises intervention after finishing the study.

To achieve the highest efficiency in the exercises, firstly the given muscles in each phase were trained separately in terms of strain and length in three primary phases and then integrated exercises were represented for each subsystem in the final phase of training. In the first two weeks, inhibit and lengthen training were done for shortened muscles known as Latissimus Dorsi, Iliopsoas hip Adductor, Iliotibial band, Hamstring, and Triceps Surae [8] [22] [23] [24]. The foam rolling was used in inhibit phase and static stretching exercises were used in lengthen phase. All inhibit and lengthen training were done by participants themselves. In the next three weeks, activation training was done in which the weak Erectors Spinae, Gluteus Maximus, Medius, Minimus Rectus Abdominis, External Abdominal Oblique, Internal Abdominal Oblique, and Transversus Abdominis muscles were targeted [8] [21] [22] [23] [24].

In the first week of activation phase, all exercises were done statically while in next two week dynamic exercises were recommended. Finally, integration training was designed with regard to stability subsystems known as Deep Longitudinal, Posterior Oblique, Anterior Oblique, and Lateral subsystems [23].

The exercise program in eight weeks and four phases (Inhibit, Lengthen, Activation, and Integration) has been represented in Table 1. All movements were selected in such a way that they didn't disturb the natural structure of the spine as much as possible and were secure for people with CMLBP.

\subsection{Statistical Analyses}

Data analysis using SPSS-22 software was performed at a significant level of $\mathrm{p} \leq$ 0.05 . Since data distribution (Shapiro-Wilk test) was non-normal for the variables of pain intensity and performance so, Wilcoxon test, and Mann-Whitney test were used respectively to compare intra- and inter-group differences. Furthermore, as data distribution was normal for the variable of the function, paired $\mathrm{t}$-test and independent t-test (Levene's test) were used respectively to compare

Table 1. Training protocol in four separated phases.

\begin{tabular}{|c|c|c|c|c|c|}
\hline Exercise & Week & Exercise Target & Repetition & Rest & Contraction \\
\hline Release & $1-2$ & $\begin{array}{l}\text { Rolling Latissimus dorsi, Iliopsoas, Hip adductor, Iliotibial } \\
\text { band, Hamstring and Triceps surae }\end{array}$ & $1 \times 60 "$ & - & Rolling foam releasing \\
\hline Stretch & $1-2$ & $\begin{array}{l}\text { Stretching Latissimus dorsi, Iliopsoas, Hip adductor, } \\
\text { Iliotibial band, Hamstring and Triceps surae }\end{array}$ & $1 \times 15^{\prime \prime}, 30 ”, 45^{\prime \prime}, 60 "$ & $30 ”$ & Static stretch \\
\hline \multirow{2}{*}{ Activation } & \multirow{2}{*}{$3-5$} & Exercises for strengthening the muscles of Gluteus & & \multirow{2}{*}{$60 "$} & \\
\hline & & Maximus, medius, and Abdominal group muscles & $3 \times 15$ rep & & Isotonic contraction \\
\hline \multirow{2}{*}{ Integration } & \multirow{2}{*}{$6-8$} & $\begin{array}{c}\text { Exercises specific to Deep longitudinal, Posterior oblique, } \\
\text { Anterior oblique and Lateral subsystems }\end{array}$ & $3 \times 6$ rep & $90 "$ & Explosive isotonic \\
\hline & & $\begin{array}{l}\text { Proprioceptive exercises with wobble board during hitting } \\
\text { taekwondo kicks to meet }\end{array}$ & $3 \times 10^{\prime}$ until losing the balance & - & balance \\
\hline
\end{tabular}


related intra-and inter-group differences.

\section{Results}

The mean and standard deviation of descriptive information obtained in the study included age, weight, height, the intensity of pain, function and performance of the elite taekwondo players with CMLBP. The intra-and inter-group changes occurred after the eight-week FT have been shown in Tables 2-4, respectively.

Table 2 shows the description the demographic characteristics and the measured variables of pain VIS, function ODI and performance SAK \& MTAK in the pre- and post-test.

The results showed that after eight-week TF, there were significant $(\mathrm{P}=0.001)$

Table 2. Description of the measured variables of (VIS), (ODI) and (SAK \& MTAK) (mean $\pm \mathrm{SD}$ ) in the pre- and post-test.

\begin{tabular}{|c|c|c|c|}
\hline Variable & - & Experimental group & Control group \\
\hline Age (years) & & $24.2 \pm 4.37$ & $25.25 \pm 5.19$ \\
\hline Mass (kg) & & $71.12 \pm 9.4$ & $81.61 \pm 17.26$ \\
\hline Height (cm) & & $179.73 \pm 6.83$ & $183.58 \pm 7.54$ \\
\hline \multirow[t]{2}{*}{ BMI } & & $22 \pm 3.14$ & $23.73 \pm 5.34$ \\
\hline & Pre-test & $38 \pm 13.9$ & $42.5 \pm 18.1$ \\
\hline \multirow[t]{3}{*}{ VAS } & Post-test & $12.3 \pm 10.1$ & $36.6 \pm 20.3$ \\
\hline & Mean difference & $-26.3 \pm 14.1$ & $-5.83 \pm 24.4$ \\
\hline & Pre-test & $16.3 \pm 8.2$ & $12.6 \pm 8.4$ \\
\hline \multirow[t]{3}{*}{ ODI } & Post-test & $6.33 \pm 6.1$ & $13.3 \pm 12.6$ \\
\hline & Mean difference & $-9.9 \pm 7.7$ & $0.66 \pm 10.4$ \\
\hline & Pre-test & $21.6 \pm 2.3$ & $20.1 \pm 1.1$ \\
\hline \multirow[t]{3}{*}{ SAK Right Leg } & Post-test & $23 \pm 2.4$ & $20.2 \pm 1.3$ \\
\hline & Mean difference & $1.7 \pm 1.3$ & $0.0001 \pm 0.04$ \\
\hline & Pre-test & $21.7 \pm 2.01$ & $20 \pm 2.1$ \\
\hline \multirow[t]{3}{*}{ SAK Left Leg } & Post-test & $23.07 \pm 1.5$ & $19.7 \pm 3.1$ \\
\hline & Mean difference & $2 \pm 1.2$ & $-0.36 \pm 1.2$ \\
\hline & Pre-test & $0.53 \pm 0.12$ & $0.55 \pm 0.07$ \\
\hline \multirow[t]{3}{*}{ MTAK Right Leg } & Post-test & $0.42 \pm 0.05$ & $0.55 \pm 0.09$ \\
\hline & Mean difference & $-0.10 \pm 0.1$ & $-0.01 \pm 0.08$ \\
\hline & Pre-test & $0.51 \pm 0.2$ & $0.54 \pm 0.07$ \\
\hline \multirow[t]{2}{*}{ MTAK Left Leg } & Post-test & $0.42 \pm 0.04$ & $0.56 \pm 0.1$ \\
\hline & Mean difference & $-0.09 \pm 0.04$ & $0.02 \pm 0.08$ \\
\hline
\end{tabular}

VAS: Visual Analogue Scale, ODI: Oswestry Disability Index, SAK: Speed of Ap Douliou Chagi kick, MTAK: Movement time of Ap Douliou Chagi kick. 
Table 3. Intra- and inter-group changes and mean difference of variables of VIS and ODI in two groups, separately.

\begin{tabular}{|c|c|c|c|c|c|}
\hline Variable & Comparison & Group & $\mathrm{U}$ & $\mathbf{Z}$ & $P$-Value \\
\hline \multirow{3}{*}{ VAS } & \multirow{2}{*}{ Intra-group differences } & Experimental $(\mathrm{N}=15)$ & - & -0.30 & $0.001^{\star}$ \\
\hline & & Control $(\mathrm{N}=12)$ & - & -0.281 & 0.779 \\
\hline & Inter-group differences & Experimental-Control & - & 2.82 & $0.004^{*}$ \\
\hline Variable & Comparison & Group & Df & $\mathrm{t}$ & $P$-Value \\
\hline \multirow{3}{*}{ ODI } & \multirow{2}{*}{ Intra-group differences } & Experimental $(\mathrm{N}=15)$ & 14 & 4.97 & $0.000^{*}$ \\
\hline & & Control $(\mathrm{N}=12)$ & 11 & 0.222 & 0.829 \\
\hline & Inter-group differences & Experimental-Control & 25 & -3.04 & $0.005^{\star}$ \\
\hline
\end{tabular}

“* = Significance Level p $\leq 0.05 ”$. VAS: Visual Analogue Scale, ODI: Oswestry Disability Index.

Table 4. Intra- and inter-group changes and mean difference of the variable of SAK \& MTAK in the two groups.

\begin{tabular}{|c|c|c|c|c|c|}
\hline Variable & Comparison & Group & $\mathrm{U}$ & $\mathrm{Z}$ & $P$-Value \\
\hline \multirow{3}{*}{ SAK Right Leg } & \multirow{2}{*}{ Intra-group differences } & Experimental $(\mathrm{N}=15)$ & - & 3.10 & $0.002^{*}$ \\
\hline & & Control $(\mathrm{N}=12)$ & - & 0.000 & 1.000 \\
\hline & Inter-group differences & Experimental-Control & 14 & -3.65 & $0.000^{*}$ \\
\hline \multirow{3}{*}{ SAK Left Leg } & \multirow{2}{*}{ Intra-group differences } & Experimental $(\mathrm{N}=15)$ & - & 3.10 & $0.002^{*}$ \\
\hline & & Control $(\mathrm{N}=12)$ & - & -0.816 & 0.414 \\
\hline & Inter-group differences & Experimental-Control & 11 & -3.75 & $0.000^{*}$ \\
\hline \multirow{3}{*}{ MTAK Right Leg } & \multirow{2}{*}{ Intra-group differences } & Experimental $(\mathrm{N}=15)$ & - & -3.06 & $0.002^{\star}$ \\
\hline & & Control $(\mathrm{N}=12)$ & - & 0.421 & 0.674 \\
\hline & Inter-group differences & Experimental-Control & 116.5 & 2.17 & $0.029^{*}$ \\
\hline \multirow{3}{*}{ MTAK Left Leg } & \multirow{2}{*}{ Intra-group differences } & Experimental $(\mathrm{N}=15)$ & - & -2.27 & $0.023^{*}$ \\
\hline & & Control $(\mathrm{N}=12)$ & - & -0.771 & 0.441 \\
\hline & Inter-group differences & Experimental-Control & 130 & 2.47 & $0.013^{*}$ \\
\hline
\end{tabular}

“* = Significance Level $\mathrm{p} \leq 0.05 ”$. SAK: Speed of Ap Douliou Chagi kick, MTAK: Movement time of Ap Douliou Chagi kick.

changes in the pain intensity of the experimental group. While it is also shown that there was a significant $(\mathrm{P}=0.004)$ difference between the experimental and control groups in terms of the mean difference in pain intensity in elite male taekwondo players with CMLBP (Table 3).

In terms of function of elite male taekwondo players with CMLBP, after an eight-week FT the results showed significant $(\mathrm{P}=0.000)$ differences in the experimental intra-group pre- and post-test and the significant $(P=0.005)$ inter-group differences between experimental and control groups (Table 3 ).

It is indicated that after eight-week FT, there was a significant $(\mathrm{p} \leq 0.05)$ difference between the mean difference of experimental intra-group pre- and post-test and the results indicated significant inter-group differences between the experimental group and control group in terms of the variable of performance (Table 4). 


\section{Discussion}

According to the results, it can be figured out that eight weeks of functional training have beneficial effects on the pain intensity, function and performance in elite male taekwondo players who suffer CMLBP. In recent years, exercise programs have been considered largely due to improving the CMLBP and many researchers have reported the effectiveness of exercise programs in the reduction of the pain intensity in people with CMLBP [1] [2] [3] [4] [25] [26].

Sherrington's law of Reciprocal Inhibition mentions that tightness of antagonists subsequently inhibits agonists [14]. So, based on Reciprocal Inhibition the results of many studies indicate that increasing flexibility in shortened muscles, such as Iliotibial band, Iliopsoas, Hamstring and Triceps Surae-are associated with the weakness of antagonist muscles and disrupt the muscle balance-and also inhibiting these muscles from trigger points can be effective in the increase of the function and the decrease of the pain in people with CMLBP [14] [27] [28]. Spinal instability is also one of the factors that some researchers have noted as the reason for the incidence of CMLBP. For example, in 2012, Johnson stated that instability in the athletes' spine and the Erectors Spinea muscles, and degeneration of joints and soft tissues surrounding the spine-which occurs due to the lack of stability in the skeletal and muscular structure of spine-can be introduced as a significant reason for increased pain intensity and functional instability. So, improving spinal stability by increasing the strength of Erector spinea muscles and surrounded soft tissues can be effective to manage CMLBP [15]. The mutual relationship between the superficial muscles of the body leads to the creation of synchronized force couples, which plays an important role in stabilizing the entire body [24]. To achieve this important aim, global joint support subsystems, called deep longitudinal, posterior oblique, anterior oblique, and lateral subsystems were trained in an integrated and coordinated form in the fourth phase.

Muscle imbalance, or the disrupted length and strain of a muscle, can lead to the disrupted reciprocal functions of muscles. For example, shortness of a muscle can increase the torque created on one side of the hip and finally disturb the direction of the sacroiliac joint. Such change will lead to the instability of the lumbar spine and sacroiliac joint and the incidence of low back pain [14] [29] [30].

Shortness of hamstring muscle is an example of muscle imbalance and its effect on muscle function. According to Reciprocal Inhibition, the shortness of hamstring muscle leads to weakening of the Gluteus Maximus muscle which is one of the causes of instability in the lumbar region [30]. Moreover, short hamstring muscle disrupts the junction of the sacroiliac joint and causes the muscles of the upper part of the trunk to compensate the disorder [30].

In addition, some researchers say prolonged trunk flexion, or excessive contraction of the Iliopsoas muscle, can increase the activity of hamstring so that during the flexion of the hip, the Ischial tuberosity experiences inferior torsion 
as a result of increased tension on the Biceps Femoris muscle [30]. This change causes increased tension in the Sacrotuberous ligament, one of the important elements in the muscular stability deep longitudinal subsystems. Further, increased tension can stimulate the mechanoreceptor and neural systems, which, in turn, eccentrically activates the hip extensors [30] [31].

On the other hand, flexion of the trunk allows pelvic anterior rotation in combination with lumbar flexion. Eccentric contraction of the hip extensors or hamstring muscles occurs during pelvic anterior rotation [30] [31]. Therefore, it is likely that increasing flexibility and decreasing strain in the hamstring muscle and strengthening the Gluteal muscles could lead to muscle balance and enhanced function of taekwondo players [30] [31].

The role of the sacroiliac joint in the development of CMLBP and the role of muscular subsystems in the joint stability is clear [29]. This joint is enclosed between the two systems; the first system refers to the structure of the bones around the joint and the second system involves muscles divided into inner layers and outer layers [29]. Global muscular subsystems constitute the outer layers of this system and, as a connected and integrated unit from the upper limbs to lower limbs of the body, provide the stability of the joint [29]. Meanwhile, there are two subsystems, which are more important than other subsystems. One of them is the posterior oblique subsystem as it creates a connection between Latissimus Dorsi muscles and Gluteus Maximus muscles, both of which are stabilizers of the sacroiliac joint. Another one is deep longitudinal subsystem, which is formed by the connection of Fibular muscle to the Biceps Femoris muscle, the latter's connection to Sacrotuberous ligament and then its connection to spine extensors on the contralateral side. Considering the importance of this ligament in the sacroiliac joint, this subsystem is of utmost importance [29]. Furthermore, in the last three weeks of the exercise program, unsustainable levels were trained by proprioceptive exercises which were done by the use of Wobble board, to increase the challenge in the muscular subsystems, which has been one of the considerable steps in the training of stability subsystems and rehabilitation of low back pain [20] [28] [31].

Regarding the movement time of kick and increased speed of kick, what can be taken into consideration are flexibility training and the increase of the range of joints motion (the most important one being the hip joint) as well as the enhancement of muscular endurance or in other words, the enhancement of muscle ability to prolonged and frequent contractions [32]. On the other hand, the effects of activation and integration training, which were specific to muscular stability subsystems and balance training, aimed to enhance biomechanical movements and the proprioceptive system cannot be ignored, which is consistent with Myer et al (2005) [33]. There are some physiological effects of activation training such as increased excitability of the motor nerves, increased motor reflex, and increased muscle strength due to changes in hormonal factors [34]. Considering the effects, this training can be a good prerequisite for plyometric 
training termed as integration training in the present protocol. Furthermore, the effects of activation training on the increase of power are an important basis for the increase in speed. Then, it can also be considered as a factor which is effective in the increased speed of taekwondo player's kick and the significance of the functional protocol [34].

As mentioned, integration training in the functional protocol is a part of plyometric training which focuses on muscular subsystems, while the plyometric training alone has significant effects on the increase of the function and performance level of players [35] [36]. The effects of plyometric training represented by Norris and other researches and include increased inhibition of antagonist muscles, better co-contraction of synergistic muscles, inhibition of neural protective mechanism and increased motor neuron excitability [22] [37]. So the effects of plyometric training can be interrelated with increased level of performance (Ap Douliou Chagi kick, in both speed and movement time Since physical and psychological factors such as stress, motivation, and so on affect the movement time of kick, it should be noted that regardless of the results of the present study, further studies with different protocols are needed to prove the effects of training on decreased movement time in both legs [38]. Moreover, there are limitations such as lack of access to specific electronic devices to evaluate SAK and MTAK as more reliable tests. Finally, by the obtained results of the effect of FT on pain and function in present study, the authors hypothesis the decreased pain and increased function and stability in low back as one the immensely important factor for improving performance (SAK \& MTAK).

\section{Conclusion}

The results of the present study show that the exercises with focus on local and global stability subsystems can be effective in reducing the pain intensity and the increase of the function and performance level in taekwondo players. This, in turn, is satisfactory for the athletes. The study suggests that researchers and students of the sports science do more research with different protocols involving shorter time table. This will help them to find a better way to make the injured players ready in a shorter time. Finally, the researchers propose their exercise protocol to specialists of sports medicine and taekwondo community, and they hope that these exercises could be a guide for future studies and lead to the better promotion of taekwondo.

\section{Acknowledgements}

The authors thank all participants and their kindly corporation.

\section{References}

[1] Zhang, Y., Tang, S., Chen, G. and Liu, Y. (2015) Chinese Massage Combined with Core Stability Exercises for Nonspecific Low Back Pain: A Randomized Controlled Trial. Complementary Therapies in Medicine, 23, 1-6.

https://doi.org/10.1016/j.ctim.2014.12.005 
[2] O'Sullivan, P. (2005) Diagnosis and Classification of Chronic Low Back Pain Disorders: Maladaptive Movement and Motor Control Impairments as Underlying Mechanism. Manual Therapy, 10, 242-255. https://doi.org/10.1016/j.math.2005.07.001

[3] Norris, C. and Matthews, M. (2008) The Role of an Integrated Back Stability Program in Patients with Chronic Low Back Pain. Complementary Therapies in Clinical Practice, 14, 255-263. https://doi.org/10.1016/j.ctcp.2008.06.001

[4] Powers, C.M., Beneck, G.J., Kulig, K., Landel, R.F. and Fredericson, M. (2008) Effects of a Single Session of Posterior-to-Anterior Spinal Mobilization and Press-Up Exercise on Pain Response and Lumbar Spine Extension in People with Nonspecific Low Back Pain. Physical Therapy, 88, 485-493. https://doi.org/10.2522/ptj.20070069

[5] Kachanathu, S.J., Alenazi, A.M., Seif, H.E., Hafez, A.R. and Alroumim, A.M. (2014) Comparison between Kinesio Taping and a Traditional Physical Therapy Program in Treatment of Nonspecific Low Back Pain. Journal of Physical Therapy Science, 26, 1185-1188. https://doi.org/10.1589/jpts.26.1185

[6] Lizier, D.T., Perez, M.V. and Sakata, R.K. (2012) Exercises for Treatment of Nonspecific Low Back Pain. Brazilian Journal of Anesthesiology, 62, 838-846. https://doi.org/10.1016/S0034-7094(12)70183-6

[7] Bono, C.M. (2004) Low-Back Pain in Athletes. Journal of Bone \& Joint SurgeryAmerican, 86, 382-396. https://doi.org/10.2106/00004623-200402000-00027

[8] Kazemi, M. and Pieter, W. (2004) Injuries at a Canadian National Taekwondo Championships: A Prospective Study. BMC Musculoskeletal Disorders, 5, 22. https://doi.org/10.1186/1471-2474-5-22

[9] Mehdizadeh, R., Rajabi, M. and Abbasi, S. (2013) Prevalence of Low Back Pain among Elite Athletes. International Research Journal of Applied and Basic Sciences, 4, 329-331.

[10] Okada, T., Nakazato, K., Iwai, K., Tanabe, M., Irie, K. and Nakajima, H. (2007) Body Mass, Nonspecific Low Back Pain, and Anatomical Changes in the Lumbar Spine in Judo Athletes. Journal of Orthopaedic \& Sports Physical Therapy, 37, 688-693. https://doi.org/10.2519/jospt.2007.2505

[11] Gordon, R. and Bloxham, S. (2016) A Systematic Review of the Effects of Exercise and Physical Activity on Non-Specific Chronic Low Back Pain. In Healthcare, 4, 2-22. https://doi.org/10.3390/healthcare4020022

[12] Chatzitheodorou, D., Kabitsis, C., Malliou, P. and Mougios, V. (2007) A Pilot Study of the Effects of High-Intensity Aerobic Exercise versus Passive Interventions on Pain, Disability, Psychological Strain, and Serum Cortisol Concentrations in People with Chronic Low Back Pain. Physical Therapy, 87, 304.

https://doi.org/10.2522/ptj.20060080

[13] Smith, J. A. and Osborn, M. (2007) Pain as an Assault on the Self: An Interpretative Phenomenological Analysis of the Psychological Impact of Chronic Benign Low Back Pain. Psychology and Health, 22, 517-534. https://doi.org/10.1080/14768320600941756

[14] Page, P., Frank, C. and Lardner, R. (2010) Assessment and Treatment of Muscle Imbalance: The Janda Approach. Human Kinetics, Champaign.

[15] Johnson, J. (2012) Functional Rehabilitation of Low Back Pain with Core Stabilizations Exercises: Suggestions for Exercises and Progressions in Athletes. All Graduate Plan B and Other Reports. 159.

[16] Fairbank, J.C. and Pynsent, P.B. (2000) The Oswestry Disability Index. Spine, 25, 2940-2953. https://doi.org/10.1097/00007632-200011150-00017 
[17] Alizadeh, H., Nasermeli, M.H., Mirzaiei, B., et al. (2014) Research Project of Special Talent Taekwondo (Pilate Iranian National Plan).

[18] Park, S.D. and Yu, S.H. (2013) The Effects of Abdominal Draw-In Maneuver and Core Exercise on Abdominal Muscle Thickness and Oswestry Disability Index in Subjects with Chronic Low Back Pain. Journal of Rehabilitation, 9, 286-291. https://doi.org/10.12965/jer.130012

[19] Notarnicola, A., Maccagnano, G., Tafuri, S., Pesce, V., Digiglio, D. and Moretti, B. (2015) Effects of Training on Postural Stability in Young Basketball Players. Muscles, Ligaments and Tendons Journal, 5, 310. https://doi.org/10.11138/mltj/2015.5.4.310

[20] Akuthota, V., Ferreiro, A., Moore, T. and Fredericson, M. (2008) Core Stability Exercise Principles. Current Sports Medicine Reports, 7, 39-44. https://doi.org/10.1097/01.CSMR.0000308663.13278.69

[21] Hwangbo, G., Lee, C.W., Kim, S.G. and Kim, H.S. (2015) The Effects of Trunk Stability Exercise and a Combined Exercise Program on Pain, Flexibility, and Static Balance in Chronic Low Back Pain Patients. Journal of Physical Therapy Science, 27, 1153-1155. https://doi.org/10.1589/jpts.27.1153

[22] Norris, C. (2011) Managing Sport Injuries. Livingstone Elsevier, Churchill.

[23] Clark, M., Lucett, S., Eds. (2010) NASM Essentials of Corrective Exercise Training. Lippincott Williams \& Wilkins, Philadelphia.

[24] Ahmed, R., Shakil-ur-Rehman, S. and Sibtain, F. (2014) Comparison between Specific Lumber Mobilization and Core-Stability Exercises with Core-Stability Exercises Alone in Mechanical Low Back Pain. Pakistan Journal of Medical Sciences, 30, 157.

[25] França, F.R., Burke, T.N., Caffaro, R.R., Ramos, L.A. and Marques, A.P. (2012) Effects of Muscular Stretching and Segmental Stabilization on Functional Disability and Pain in Patients with Chronic Low Back Pain: A Randomized, Controlled Trial. Journal of Manipulative and Physiological Therapeutics, 35, 279-285. https://doi.org/10.1016/j.jmpt.2012.04.012

[26] Malai, S., Pichaiyongwongdee, S. and Sakulsriprasert, P. (2015) Immediate Effect of Hold-Relax Stretching of Iliopsoas Muscle on Transversus Abdominis Muscle Activation in Chronic Non-Specific Low Back Pain with Lumbar Hyperlordosis. Journal of the Medical Association of Thailand = Chotmaihet thangphaet, 98, S6-S11.

[27] Chang, W.D., Lin, H.Y. and Lai, P.T. (2015) Core Strength Training for Patients with Chronic Low Back Pain. Journal of Physical Therapy Science, 27, 619-622. https://doi.org/10.1589/jpts.27.619

[28] Brukner, P. (2012) Brukner \& Khan's Clinical Sports Medicine. McGraw-Hill, North Ryde.

[29] Hertling, D. and Kessler, R.M. (2006) Management of Common Musculoskeletal Disorders: Physical Therapy Principles and Methods. Lippincott Williams \& Wilkins, Philadelphia.

[30] Kim, M.H. and Yoo, W.G. (2013) Comparison of the Hamstring Muscle Activity and Flexion-Relaxation Ratio between Asymptomatic Persons and Computer Work-Related Low Back Pain Sufferers. Journal of Physical Therapy Science, 25, 535-536. https://doi.org/10.1589/jpts.25.535

[31] Kofotolis, N. and Kellis, E. (2007) Effects of Two 4-Week Proprioceptive Neuromuscular Facilitation Programs on Muscle Endurance, Flexibility, and Functional Performance in Women with Chronic Low Back Pain. Journal of Orthopaedic \& Sports Physical, 37, 424. 
[32] Vasileiou, N., Michailidis, Y., Gourtsoulis, S., Kyranoudis, A. and Zakas, A. (2013) The Acute Effect of Static or Dynamic Stretching Exercises on Speed and Flexibility of Soccer Players. Journal of Sport and Human Performance, 1, 306-315.

[33] Myer, G.D., Ford, K.R., Palumbo, O.P. and Hewett, T.E. (2005) Neuromuscular Training Improves Performance and Lower-Extremity Biomechanics in Female Athletes. The Journal of Strength \& Conditioning Research, 19, 51-60. https://doi.org/10.1519/00124278-200502000-00010

[34] Cronin, J.B. and Hansen, K.T. (2005) Strength and Power Predictors of Sports Speed. The Journal of Strength \& Conditioning Research, 19, 349-357. https://doi.org/10.1519/00124278-200505000-00019

[35] Wang, Y.C. and Zhang, N. (2016) Effects of Plyometric Training on Soccer Players (Review). Experimental and Therapeutic Medicine, 12, 550-554. https://doi.org/10.3892/etm.2016.3419

[36] Taheri, E., Nikseresht, A. and Khoshnam, E. (2014) The Effect of 8 Weeks of Plyometric and Resistance Training on Agility, Speed and Explosive Power in Soccer Players. European Journal of Experimental Biology, 4, 383-386.

[37] Chmielewski, T.L., Myer, G.D., Kauffman, D. and Tillman, S.M. (2006) Plyometric Exercise in the Rehabilitation of Athletes: Physiological Responses and Clinical Application. Journal of Orthopaedic \& Sports Physical Therapy, 36, 308-319. https://doi.org/10.2519/jospt.2006.2013

[38] Roach, A., Lash, D., Loomis, E., Sinnen, T. and DeYoung, M. (2014) The Effects of Exercise on Reaction Time. Journal of Advanced Student Science, 601, 1-18.

Submit or recommend next manuscript to SCIRP and we will provide best service for you:

Accepting pre-submission inquiries through Email, Facebook, LinkedIn, Twitter, etc. A wide selection of journals (inclusive of 9 subjects, more than 200 journals)

Providing 24-hour high-quality service

User-friendly online submission system

Fair and swift peer-review system

Efficient typesetting and proofreading procedure

Display of the result of downloads and visits, as well as the number of cited articles

Maximum dissemination of your research work

Submit your manuscript at: http://papersubmission.scirp.org/

Or contact health@scirp.org 